\title{
Thermal Error Measurement and Analysis of Vertical Machining Center
}

\author{
Yumeng $\mathrm{Ma}^{1}$, Huanyong $\mathrm{Cui}^{2}$, Changchun $\mathrm{Li}^{1}$, Changzhong $\mathrm{Wu}^{1}$, and Zhenyuan Zhao ${ }^{3}$ \\ ${ }^{1}$ University of Jinan, School of Mechanical Engineering, 250022 Jinan, China \\ ${ }^{2}$ University of Jinan, School of Automation and Electrical Engineering, 250022 Jinan, China \\ ${ }^{3}$ Guanhong Intelligent mechanical equipment Co.Ltd, 252500 Liaocheng, China
}

\begin{abstract}
In this paper, the thermal calculation and thermal-structural coupling analysis of the vertical machining center are carried out to obtain the theoretical values of thermal generation and thermal displacement. Combined with the thermal structure analysis of vertical machining center, sensors are placed at the key positions with large thermal displacement to measure and analyze the thermal error data, and the law of temperature and thermal deformation of machining center is found out. This research provides theoretical basis for thermal error compensation.
\end{abstract}

\section{Introduction}

In the working process of the machining tool, due to the role of various heat sources, a large amount of heat will be generated to cause an increase in temperature. The uneven distribution of temperature field causes relative displacement between workpiece and the tool, which will reduce machining accuracy [1]. A large number of studies have shown that the manufacturing error caused by the thermal deformation of machine tool generally accounts for $40 \%-60 \%$ of total error processing. Especially in precision machining, workpiece machining accuracy affected by thermal error is more significant $[2,3]$.

In recent years, researchers have done a lot of research on modeling and compensation of thermal error. Only a few researchers have tackled this problem with some success. Through theoretical analyze, simulation and experiment, Li Yang et al. found that thermal error is determined by multiple variables, and thus established a multivariate model [4]. Eskandari et al. used neural network and fuzzy logic to compensate the axial thermal error of the machine tool, experiments have proved that both models can achieve thermal error prediction with good reliability [5]. Neugebauer et al. studied the thermal interaction between machining process and workpiece, and proposed a new method to reduce thermal error by optimizing cutting parameters [6].

Using ANSYS Work-bench software to calculate its temperature field and thermal deformation, the research object of this paper is the ZH-850E vertical machining center. According to the analysis results, the purpose is to find out the law of temperature change and thermal deformation, the sensor is placed at the position with the highest temperature and maximum deformation, and the actual data measured is analyzed.

\section{Heating calculation}

The Finite element method is used to analyze the steadystate thermal structure for various machine tools, and the most important thing is to deal with the boundary conditions. Considering heat source and convection heat transfer for vertical machining center, the heat source mainly includes spindle motor heating, cutting heat and bearing friction heat, and the convection forms are divided into natural convection and forced convection.

\subsection{The calculation of calorific value for spindle motor}

The calorific value is calculated as follows:

$$
Q=P(1-\eta)
$$

Where $P$ is the motor rated power, $\eta$ is the motor rated efficiency.

\subsection{The calculation of cutting heat}

In the cutting process, the energy consumed by the vertical machining center is basically converted into cutting heat and it directly affects the machining accuracy. Through the chips, workpieces, cutters and surrounding media, the cutting heat is transmitted to the worktable and other parts. The calculation formula of cutting heat is [7]:

$$
Q=F v+\left(F_{f} n_{v} f\right) / 1000
$$

Where: $F, F_{f}, v, n_{v}$ and $f$ are cutting force, feed force, cutting speed, workpiece speed and feed rate, respectively. 


\subsection{The calculation of bearing calorific value}

The bearing heating is mainly caused by the friction torque and lubricant between the roller and ring [8], and the calorific formula can be expressed as:

$$
Q=2 \pi M n / 60
$$

Where: $M$ and $\mathrm{n}$ are friction torque and bearing speed, respectively.

For approximate estimation, the formula of friction torque can be given as:

$$
M=0.5 \mu F d
$$

Where: $\mu, d$ and Fare friction coefficient, inner diameter of the bearing and equivalent dynamic load, respectively.

\subsection{The calculation of convection heat transfer coefficient}

The convection heat transfer coefficient is expressed as heat transfer between solid and fluid. Based on the Nusselt criterion Formula, the convection heat transfer coefficient $\mathrm{h}$ can be written as:

$$
h=N u \lambda / L
$$

Where: $N u, \lambda$ and $L$ are the average Nusselt coefficient, the heat conductivity coefficient of fluid and the characteristic size, respectively.

\subsubsection{The heat transfer for natural convection}

The Grashoff number of heat transfer for natural convection can be expressed as [9]:

$$
\begin{aligned}
N u & =C(G r P r)^{n} \\
G r & =\left(g \beta L^{3} \Delta t\right) / v^{2}
\end{aligned}
$$

Where: $\mathrm{C}$ and $\mathrm{n}$ are constants; $G r, P r, g, \beta, L$, and $\Delta t$ are the Graschoff number, the Plante number, the gravitational acceleration, the coefficient of volume change, the characteristic size, the temperature difference and the kinematic viscosity, respectively.

\subsubsection{The heat transfer for forced convection}

Because of the friction heating at the bearing, the temperature of the spindle and the box is increased greatly. Using the cooling water to cooling is belonged to the heat transfer for forced convection in the tube, and the formula for convection heat transfer [10] can be given as:

The State for laminar is :

$$
N u=0.5 \operatorname{Re}^{0.33} \operatorname{Pr}^{0.43} \mathrm{Gr}^{0.1}(\operatorname{Pr} / \operatorname{Pr} \omega) 0.25 k
$$

The State for turbulence is :

$$
N u=0.21 \operatorname{Re}^{0.8} \operatorname{Pr}^{0.43} \mathrm{Gr}^{0.1}(\operatorname{Pr} / \operatorname{Pr} \omega) 0.25
$$

Where: $R e=\omega l / v, \omega, l, v, \operatorname{Pr}$ and $K$ are Reynolds number, velocity, characteristic size, kinematic viscosity, Plante number and correction coefficient, respectively.

\subsubsection{The convective heat release for rotating axis}

Because of the rotation of the spindle, the convective heat transfer between the spindle and air will be accelerated, and the calculation formula of the convective heat release for rotating axis [11] can be written as:

$$
N u=0.133 \operatorname{Re}^{2 / 3} \operatorname{Pr}^{1 / 3}
$$

\section{Analysis of temperature and thermal displacement based on ansys workbench}

Ignoring the minor part that is less affected by temperature changes to simplify the complex structure of ZH-850E vertical machining center. The SOILD95 is used for meshing to establish a finite element model, because the SOILD95 can absorb irregularly shaped elements without loss of precision. As shown in Fig. 1, including 371215 nodes, 188829 elements.

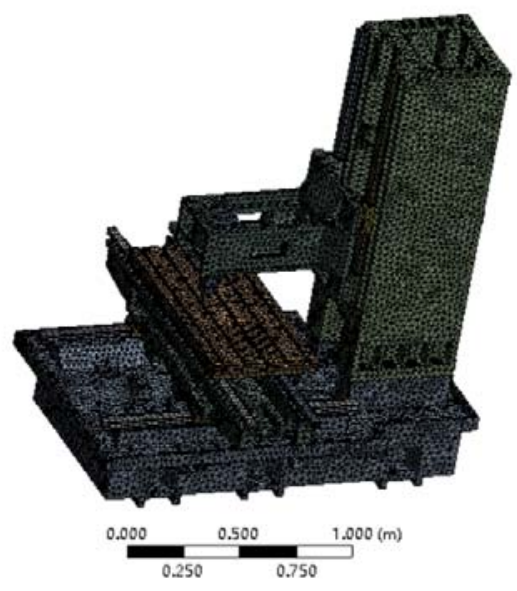

Fig. 1. Finite element model.

\subsection{Steady temperature field analysis}

According to formula (1), formula (2) and formula (3), when the spindle speed is $5000 \mathrm{r} / \mathrm{min}$, the spindle motor generates heat is $1650 \mathrm{~W}$ and the cutting heat is $3950 \mathrm{~W}$. The heat generated by the front, middle and end bearings are $287.3 \mathrm{~W}, 216.5 \mathrm{~W}$ and $67.2 \mathrm{~W}$, the heat transfer coefficients of each component are shown in Table 1.

Table 1. Heat transfer coefficient $/\left(\mathrm{W} \cdot \mathrm{m}^{2}{ }^{\circ} \mathrm{C}^{-1}\right)$.

\begin{tabular}{ccccccc}
\hline Bed ide carria: & $\begin{array}{c}\text { Work } \\
\text { bench }\end{array}$ & $\begin{array}{c}\text { Upright } \\
\text { column }\end{array}$ & $\begin{array}{c}\text { Head } \\
\text { stock }\end{array}$ & ont bearir $\begin{array}{c}\text { End } \\
\text { bearing }\end{array}$ \\
3.2 & 4.8 & 5.4 & 2.6 & 9.6 & 82.5 & 63.7 \\
\hline
\end{tabular}

Setting the analysis type as steady-state thermal analysis, as shown in Fig. 2, the steady-state thermal field of the vertical machining center is obtained. 


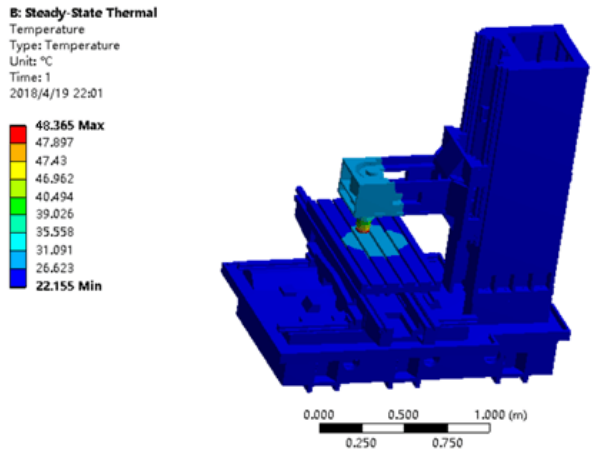

Fig. 2. Steady-state temperature field.

As can be seen from Fig. 2, the temperature field of the vertical machining center is unevenly distributed. The highest temperature appears at the front of the spindle, reaching $48.365^{\circ} \mathrm{C}$, which provides a theoretical basis for the distribution of the rear temperature sensor.

\subsection{Thermal-structural coupling analysis}

The steady-state temperature field of the vertical machining center is subjected to thermal structural coupling analysis as a temperature load, and thermal strain and total deformation can be obtained. As shown in Fig. 3, the front end of the spindle has the largest deformation, which can reach $0.05044 \mathrm{~mm}$. The rising temperature of the spindle caused the expansion and the tilt occurred. It can be seen that there are deformations in the three directions of $\mathrm{X}, \mathrm{Y}$ and $\mathrm{Z}$, which also provides a theoretical basis for the arrangement of the displacement sensor in the measurement experiment of the thermal error.
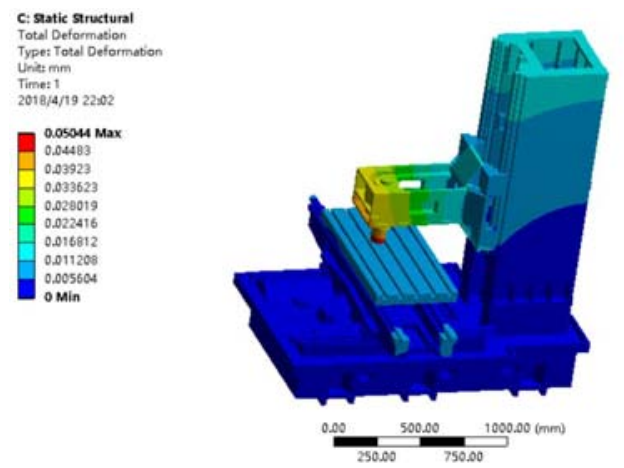

Fig. 3. Steady-state thermal deformation.

\section{Thermal error measurement and analysis}

\subsection{Experimental set-up and procedure}

In order to measure the temperature increase and the thermal deformation of the vertical machining center, as shown in Fig. 4, digital temperature sensor DS18B20 and eddy current displacement sensor were used in this experiment. The highest resolution of DS18B20 can reach $0.0625^{\circ} \mathrm{C}$. The temperature conversion time is $750 \mathrm{~ms}$, the measuring range is $-55^{\circ} \mathrm{C} \sim+125^{\circ} \mathrm{C}$, which meets the experimental requirements. Eddy current displacement sensor has the advantages of non-contact measurement, good dynamic response and strong antiinterference ability. After calibrating it, the accuracy is $1 \mu \mathrm{m}$, which can meet the requirement of measuring the accuracy of thermal displacement.

In order to minimize the random error in the measurement process, the $\mathrm{X}, \mathrm{Y}$, and $\mathrm{Z}$ directions are repeated three times under the same working conditions, and the average value is taken as the measurement result [12]. As shown in Fig. 5, the eddy current displacement sensor is mounted on the headstock to align it with the spindle front end position. Temperature and thermal errors need to be measured simultaneously, so that each set of thermal error data corresponds to a set of temperature data.

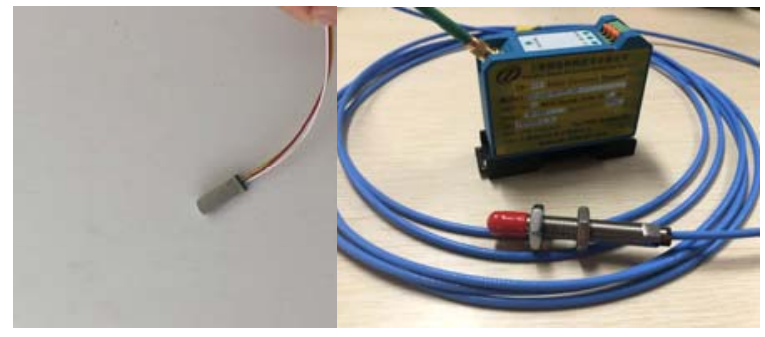

Fig. 4. Temperature sensor and displacement sensor.

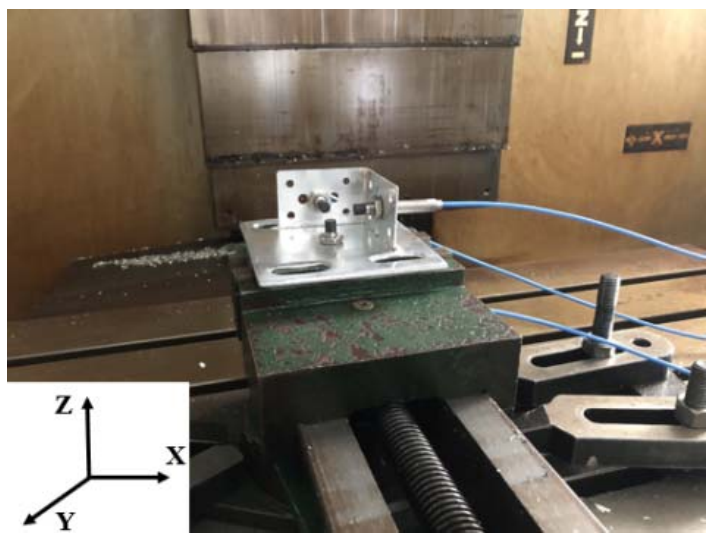

Fig. 5. Thermal error measurement and displacement sensor.

The position of the temperature measurement point is shown in Table 2.

Table 2. Position of the temperature measurement point.

\begin{tabular}{cc}
\hline Number & Position \\
\hline T1 $、$ T3 & Outside the spindle flange \\
T2 & Outside of the spindle bearing \\
T4、T5、T6 & Lower part of the headstock \\
T7 T8、T9 & Upper part of the headstock \\
\hline
\end{tabular}

\subsection{Experimental results and discussion}

Take the measurement results of spindle speed $5000 \mathrm{r} / \mathrm{min}$ condition as an example, and the T2 group with the largest correlation coefficient was selected as the key temperature point [13] to find out the trend 
between temperature and thermal deformation. Experimental results of key temperature and thermal deformation are shown in Table 3.

Table 3. Experimental results of key temperature and thermal deformation. (5000r/min)

\begin{tabular}{ccccc}
\hline Time $/$ min & Temperature $/{ }^{\circ} \mathrm{C}$ & \multicolumn{3}{c}{ Deformation $/ \mu \mathrm{m}$} \\
\hline 1 & $\mathrm{~T}_{2}$ & $\mathrm{X}$ & $\mathrm{Y}$ & $\mathrm{Z}$ \\
2 & 27.2 & 0.0 & 0.0 & 0.0 \\
3 & 27.2 & -0.1 & -0.1 & 0.0 \\
$\mathbf{i}$ & $\mathbf{i}$ & $\mathbf{i}$ & $\mathbf{i}$ & $\mathbf{i}$ \\
139 & 41.2 & 8.5 & 18.7 & 41.2 \\
140 & 41.2 & 8.5 & 18.7 & 41.2 \\
\hline
\end{tabular}

The thermal deformation in the Z-axis direction is the largest, the $\mathrm{Y}$-axis direction is the second, and the $\mathrm{X}$ direction change is the smallest. The trend of temperature and thermal deformation with time is shown in Fig. 6.

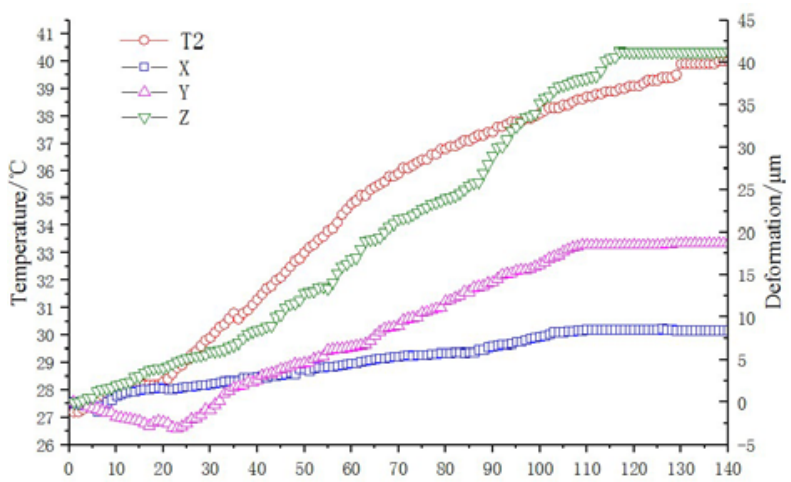

Fig. 6. Trend of temperature and thermal deformation with time.

Since the spindle has deformations in the three directions of $\mathrm{X}, \mathrm{Y}$ and $\mathrm{Z}$, a space Cartesian coordinate system can be established. Using each set of thermal deformation data as a coordinate point $\mathrm{P}(\mathrm{x}, \mathrm{y}, \mathrm{z})$, then the length of $O P$ is the deformation amount in three directions. The result of the calculation is $46.036 \mu \mathrm{m}$, the length can be expressed as:

$$
O P=\sqrt{ }\left(x^{2}+y^{2}+z^{2}\right)
$$

\section{Conclusions}

(1) The error between the simulation results and the experiment results is basically controlled within $15 \%$ as shown in Table 4. It is proved that the simulation results are reliable, which is basically consistent with the actual situation.

Table 4. Value of simulation and experiment.

\begin{tabular}{cccc}
\hline Project & Simulation & Experiment & Error $(\%)$ \\
\hline Temperature $\left({ }^{\circ} \mathrm{C}\right)$ & 48.4 & 41.2 & 14 \\
Deformation $(\mu \mathrm{m})$ & 50.440 & 46.036 & 8 \\
\hline
\end{tabular}

(2) The thermal equilibrium time of the vertical machining center is about $130 \mathrm{~min}$, the thermal deformation also tends to be stable with temperature, and the thermal deformation has a good correspondence with temperature, which provides a theoretical basis for thermal error modeling and compensation.

\section{References}

1. S.L. Guo, D.P. Liu, Q. Qian, et al. Thermal Finite Element Analysis of the Vertical Machining Center [J]. Mechanical Design \& Manufacturing, 6568(2014)

2. R. Ramesh, M.A. Mannan.Error compensation in machine tools - a review : Part II: thermal errors [J]. International Journal of Machine Tools \& Manufacture, 40(9):1257-1284(2000).

3. P.M. Ferreira, C.R. Liu. A Method for Estimating and Compensating Quasistatic Errors of Machine Tools [J]. Journal of Engineering for Industry, 115(1):149(1993).

4. Y. Li, W. Zhao, W. Wu. Thermal error modeling of the spindle based on multiple variables for the precision machine tool $[\mathrm{J}]$. International Journal of Advanced Manufacturing Technology,72(9):14151427(2014).

5. S. Eskandari, B. Arezoo, A. Abdullah. Thermal Errors Modeling of a CNC Machineâs Axis Using Neural Network and Fuzzy Logic [J]. Applied Mechanics \& Materials, 110-116:2976-2982(2012).

6. R. Neugebauer, W.G. Drossel. Thermal Interactions between the Process and Workpiece [J]. Procedia Cirp, 4(5):63-66(2012).

7. B.H. Lu. Foundation of Mechanical Manufacturing Technology [M], (Mechanical Industry Press, 2008)

8. J.Y. Zou, M. Xiao, Y. He. Thermal Structure and Thermal Balance Analysis of Machine Tools Based on ANSYS Workbench [J]. Machinery, 8-11(2012).

9. H.M. Sun, Y.Z. Wang. The Finite Element Analysis of Thermal Property of High-Speed Spindle System in Vertical Machining Center [J].Advanced Materials Research, 433-440:567-571(2012)

10. J.S. Wang, Z.Y. Weng, C.Y. Yao, et al. Application of ANSYS in the analysis of thermal characteristics on $\mathrm{CNC}$ milling machine [J].Journal of Zhejiang University of Technology, 32(3):255-259(2004)

11. A.R. Alavizadeh, A. Zargari, W.R. Grise. The application of ANSYS software in analyzing and predicting thermal behaviour [C].Electrical Insulation Conference and Electrical Manufacturing \& Coil Winding Conference, 1999. Proceedings. IEEE, 2002:583-588.

12. Z. Du, S. Zhang, M. Hong. Development of a multistep measuring method for motion accuracy of $\mathrm{NC}$ machine tools based on cross grid encoder [J]. International Journal of Machine Tools \& Manufacture, 50(3):270-280(2010)

13. C.H. Wu, Y.T. Kung. Thermal analysis for the feed drive system of a CNC machine center [J]. International Journal of Machine Tools \& Manufacture, 43(15):1521-1528(2003). 